\title{
MODELOS DE DETERMINAÇÃO DE ÁREA FOLIAR EM FEIJÃO CAUPI
}

OLIVEIRA, Raimundo Leonardo Lima de ${ }^{1}$ LIMA, Layla Gerusa Souza MOREIRA, Antonio Robson ${ }^{1}$ SOUZA, Leane Castro de ${ }^{1}$

COSTA, Antonia Vanderlane Albuquerque da ${ }^{1}$ SILVA, Raimundo Thiago Lima da

RESUMO: O feijão caupi é uma das leguminosas mais consumidas nas regiões Norte e Nordeste do Brasil, representando uma importante fonte de proteína, energia, fibras e minerais. Com o objetivo de obter equações que, por meio de parâmetros lineares dimensionais das folhas, que permitam estimar a área foliar do feijão caupi, das cultivares BRS Potengi e BRS Tracuateua, foi conduzido um experimento na Universidade Federal Rural da Amazônia no Campus de Capitão Poço - PA. A área foliar foi determinada pelo método dos discos. Ajustaram-se modelos lineares, lineares sem intercepto, quadráticos, cúbicos, logarítmicos, exponenciais e potenciais entre área foliar e o comprimento, a largura e seus produtos (comprimento x largura), sendo eliminados os que apresentaram coeficiente de determinação menor do que 0,90. A estatística utilizada para avaliar o desempenho dos modelos foi o coeficiente de correlação de Pearson (r), o de determinação $\left(\mathrm{R}^{2}\right)$, a raiz do quadrado médio do erro, o erro absoluto médio, o índice d de Willmott e o índice de Camargo e Sentelhas (CS). Para a cv BRS Potengi as medidas de área foliar podem ser estimadas com boa precisão a partir de equações quadráticas, cúbicas, potencial e linear e, para a cv BRS Tracuateua os modelos matemáticos de melhor desempenho foram o linear, quadrático e potencial.

Palavras-chave: BRS Potengi. Coeficiente de determinação. Dimensões do limbo foliar.

SUMMARY: The cowpea is one of the most widely consumed legumes in the North and Northeast of Brazil, representing an important source of protein, energy, fiber and minerals. In order to obtain equations through linear dimensions of leaves, to estimate the leaf area of the cowpea, the BRS Potengi and BRS Tracuateua, an experiment was conducted in the Amazonia Federal Rural Universidade in Capitão Poço Campus - PA. The leaf area was determined by the discs. Set up linear, linear without intercept, quadratic, cubic, logarithmic, exponential and potential between leaf area and length, width and the product (length $\mathrm{x}$ width), being eliminated those who had coefficient of determination lower than 0,90 . The statistic used to evaluate the performance of the models was the Pearson correlation coefficient $(r)$, the determination $\left(R^{2}\right)$, the root mean square error, mean absolute error, $d$ index Willmott and Camargo index and Sentelhas (CS). For BRS Potengi the leaf area measurements can be estimated with good accuracy from quadratic equations, cubic, potential and linear and for BRS Tracuateua mathematical models to better performance were linear, quadratic and potential.

Keywords: BRS Potengi. Determination coefficient. Dimensions of the leaf blade.

\section{INTRODUÇÃO}

O feijão caupi (Vigna unguiculata (L.) Walp.) é uma das leguminosas mais consumidas nas regiões Norte e Nordeste do Brasil, representando uma importante fonte de proteína, energia, fibras e minerais, além de gerar emprego e renda para a população (OLIVEIRA et al., 2015).

No estado do Pará é cultivado, tradicionalmente, por pequenos agricultores no qual foi introduzido principalmente por imigrantes nordestinos e, desde então, passou a ser um importante componente dos sistemas de produção da agricultura paraense (SANTOS et al., 2009). A área plantada de feijão caupi no

\footnotetext{
${ }^{1}$ Graduando em Agronomia da Universidade Federal Rural da Amazônia, Campus de Capitão Poço, PA.

${ }^{2}$ Dr. Engenheiro Agrônomo, Professor de Engenharia de água e solo dos cursos de Agronomia e Engenharia Florestal, da Universidade Federal Rural da Amazônia, Campus de Capitão Poço, PA.
} 
Pará em 2012 foi aproximadamente 51.555 hectares e a produção alcançada foi contabilizada em torno de 35.512 toneladas por hectare (SAGRI, 2015).

O primeiro passo para se estudar o crescimento das plantas é o conhecimento da área foliar, pois esta é um parâmetro importante para o entendimento da fotossíntese, interceptação luminosa, uso da água e nutrientes e o potencial produtivo. Neste contexto, torna-se fundamental o conhecimento da área foliar para ajudar o entendimento do processo de partição de assimilados e na determinação do número de folhas ideal nas condições climáticas do Brasil (BLANCO; FOLLEGATTI, 2005; LUCENA et al., 2011). Portanto, mensurar esta variável é de extrema importância para avaliar o crescimento e desenvolvimento das plantas (SCHMILDT et al., 2015).

Vários são os métodos para se obter a área foliar, cuja escolha depende do objetivo principal da medida, da necessidade, ou não, de destruição da planta, da necessidade da área total das folhas ou apenas da área individual. Alguns estudos mostram que o método não destrutivo pode ser indicado para estimar satisfatoriamente a área foliar em substituição à análise destrutiva (SACHET et al., 2015).

Assim, o presente trabalho tem por objetivo obter modelos matemáticos eficientes, para estimar a área foliar de feijão caupi, das cultivares BRS Potengi e BRS Tracuateua no município de Capitão Poço no Estado do Pará, utilizando-se parâmetros dimensionais de folhas de diferentes tamanhos.

\section{MATERIAL E MÉTODO}

O trabalho foi desenvolvido na Universidade Federal Rural da Amazônia, no período de Junho de 2012 a Setembro de 2012 com as cultivares de feijão caupi BRS Potengi e BRS Tracuateua, distribuídas no espaçamento $0,5 \mathrm{~m}$ entre linhas e $0,2 \mathrm{~m}$ entre plantas, localizado no município de Capitão Poço no Estado do Pará. A adubação de plantio consistiu de $70 \mathrm{~kg} \mathrm{ha}^{-1}$ de $\mathrm{P}_{2} \mathrm{O}_{5}$ e $40 \mathrm{~kg} \mathrm{ha}^{-1}$ de $\mathrm{K}_{2} \mathrm{O}$ (EMBRAPA, 2010).

Segundo a classificação de Köppen, o clima da região é do tipo Am com precipitação anual em torno de $2.500 \mathrm{~mm}$, com uma curta estação seca entre setembro e novembro (precipitação mensal em torno de $60 \mathrm{~mm}$ ), temperatura média de $26^{\circ}$ e umidade relativa do ar entre $75 \%$ e $89 \%$ nos meses com menor e maior precipitação, respectivamente (SCHWART, 2007).

$\mathrm{Na}$ determinação da área foliar (AF), foram coletadas aleatoriamente 6 folhas de 18 plantas de cada cultivar nos respectivos estádios fenológico da cultura: período vegetativo $\left(\mathrm{F}_{1}\right)$, surgimento dos botões florais $\left(\mathrm{F}_{2}\right)$, maturação fisiológica $\left(\mathrm{F}_{3}\right)$ e o ponto de colheita $\left(\mathrm{F}_{4}\right)$. Todas as folhas não tinham qualquer dano ou ataque de doenças ou pragas.

As folhas foram medidas coletando-se então o comprimento ao longo da nervura central (C) e a largura máxima perpendicular à nervura central $(\mathrm{L})$ do limbo foliar, com régua milimetrada. Em seguida foi calculado o produto do comprimento pela largura $(\mathrm{CxL})$ do limbo foliar. Com auxílio de um calador com diâmetro de $13 \mathrm{~mm}$, obteve-se o número máximo possível de discos do limbo, incluindo as nervuras (SILVA et al., 2013).

Individualmente cada amostra de discos e o restante das folhas foram acondicionados separadamente em sacos de papel e levados à estufa de secagem com ventilação forçada, a uma temperatura de $65^{\circ} \mathrm{C}$, por 72 horas até peso constante. Para a determinação da massa seca das duas partes foi utilizada uma balança eletrônica com precisão de $5 \mathrm{mg}$. A área total de cada folha (AF), em $\mathrm{cm}^{2}$, foi calculada através da equação 1 abaixo (SILVA et al., 2013). 


$$
A F=\frac{\left(M S f^{*} A T d\right)}{M S d}
$$

Em que:

MSd - massa seca dos discos, (g);

ATd - área total dos discos, $\left(\mathrm{cm}^{2}\right)$;

MSf - massa seca total das folhas (g).

Com os dados de $\mathrm{C}, \mathrm{L}, \mathrm{CxL}$ e da $\mathrm{AF}$ das folhas restantes, modelou-se a área foliar, determinada pelo método dos discos $(\mathrm{Y})$ em função do $\mathrm{C}$, da $\mathrm{L}$ e do $\mathrm{C} \times \mathrm{L}$, por meio dos modelos: quadrático $(\mathrm{Y}=\mathrm{a}+$ $\left.\mathrm{bx}+\mathrm{cx}^{2}\right)$, cúbico $\left(\mathrm{Y}=\mathrm{a}+\mathrm{bx}+\mathrm{cx}^{2}+\mathrm{dx}^{3}\right)$, potência $\left(\mathrm{Y}=\mathrm{ax} \mathrm{x}^{\mathrm{b}}\right)$, linear $(\mathrm{Y}=\mathrm{a}+\mathrm{bx})$, linear sem intercepto $(\mathrm{Y}=\mathrm{bx})$ e exponencial $\left(\mathrm{Y}=\mathrm{e}^{\mathrm{X}}\right)$.

Para a validação de cada modelo de estimativa de área foliar, foram utilizados as 6 folhas das 18 plantas de cada cultivar em cada estádio fenológico obtendo os valores estimados pelo modelo (Ye) e valores observados (Yo). Para cada modelo, foi ajustada uma regressão linear simples (Ye = a + bYo) da área foliar estimada pelo modelo (variável dependente) em função da área foliar observada (variável independente) (SILVA, et al., 2013).

Foram calculados os coeficientes de correlação linear de Pearson (r) o de determinação da regressão $\left(\mathrm{R}^{2}\right)$ entre Ye e Yo. Também foi calculado o erro absoluto médio (EAM), a raiz do quadrado médio do erro (RQME), o índice d de Willmott (WILLMOTT, 1981) e o índice CS (CAMARGO; SENTELHAS, 1997), por meio, respectivamente, das (Eqs. 2, 3, 4 e 5).

$$
\begin{array}{r}
E A M=\frac{\sum_{i=1}^{n}|Y e-Y o|}{n} \\
R Q M E=\sqrt{\frac{\sum_{i=1}^{n}(Y e-Y o)^{2}}{n}} \\
d=1-\left(\frac{\sum_{i=1}^{n}(Y e-Y o)^{2}}{\sum_{i=1}^{n}(|Y e-\bar{Y}|+|Y o-\bar{Y}|)^{2}}\right) \\
C S=r . d
\end{array}
$$

Em que:

Ye - valores estimados de área foliar, $\left(\mathrm{cm}^{2}\right)$;

Yo - valores observados de área foliar por meio do método dos discos, $\left(\mathrm{cm}^{2}\right)$;

$\bar{Y}$ - média dos valores observados;

n - número de folhas.

As análises estatísticas dos resultados do experimento foram realizadas utilizando o aplicativo Office Excel. 


\section{RESULTADO E DISCUSSÃO}

Para a determinação da área foliar do feijão caupi cultivar BRS Potengi, foram considerados os modelos matemáticos mais eficientes que estimassem esta variável com boa precisão.

Foram selecionados para cada variável independente C, L e CxL, e em cada fase fenológica da cultura $\left(\mathrm{F}_{1^{-}}\right.$fase vegetativa; $\mathrm{F}_{2^{-}}$surgimento dos botões florais; $\mathrm{F}_{3^{-}}$maturação fisiológica e $\mathrm{F}_{4^{-}}$ponto de colheita), pelo menos um modelo com o melhor ajuste e coeficiente de determinação da regressão ( $\left.\mathrm{R}^{2}\right)$ superior a 0,90 , para posteriormente fazer a linearização das equações matemáticas geradas, como apresentado nas Figuras 1 e 2.

Figura 1. Modelos de regressão para as variáveis independentes L e C x L (A e B) para a fase vegetativa $\left(\mathrm{F}_{1}\right)$, obtidas em Capitão Poço-PA, Brasil, 2012.

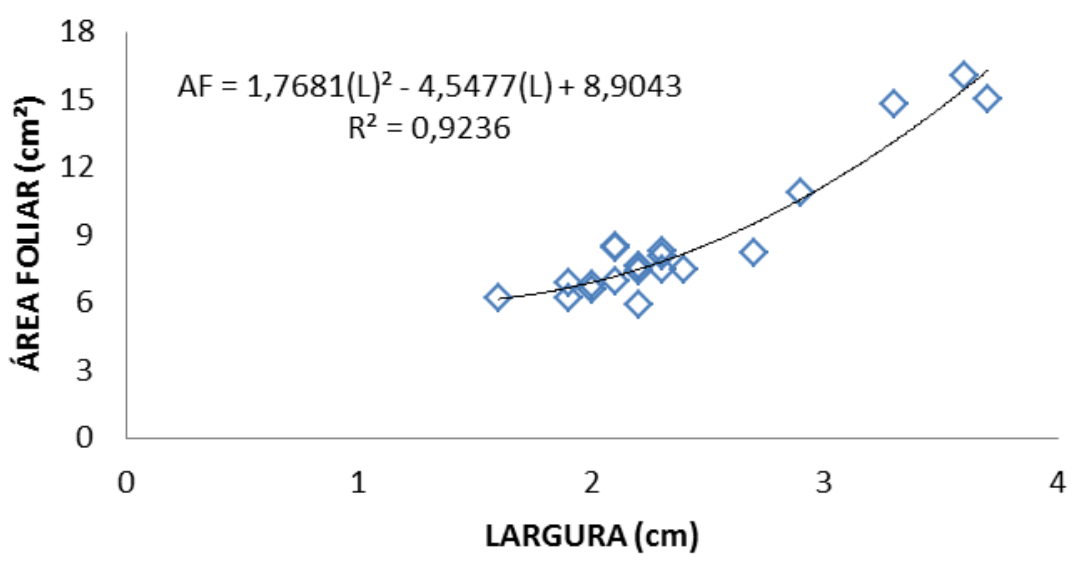

(A)

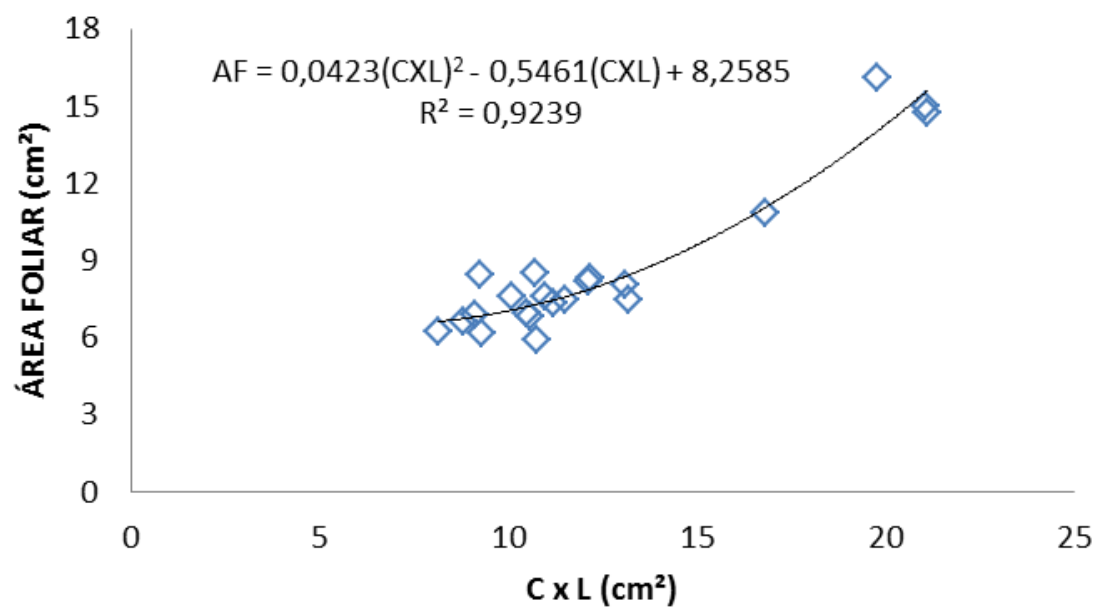

(B)

No estádio de maturação fisiológica da planta para cada variável independente, houve pelo menos um modelo que representasse com boa precisão a área foliar, conforme a Figura 2, abaixo. 
Figura 2. Modelos de regressão para as variáveis independentes C, L e C x L (A, B e C) para a fase de maturação fisiológica $\left(\mathrm{F}_{3}\right)$ respectivamente, obtidas em Capitão Poço-PA, Brasil, 2012.

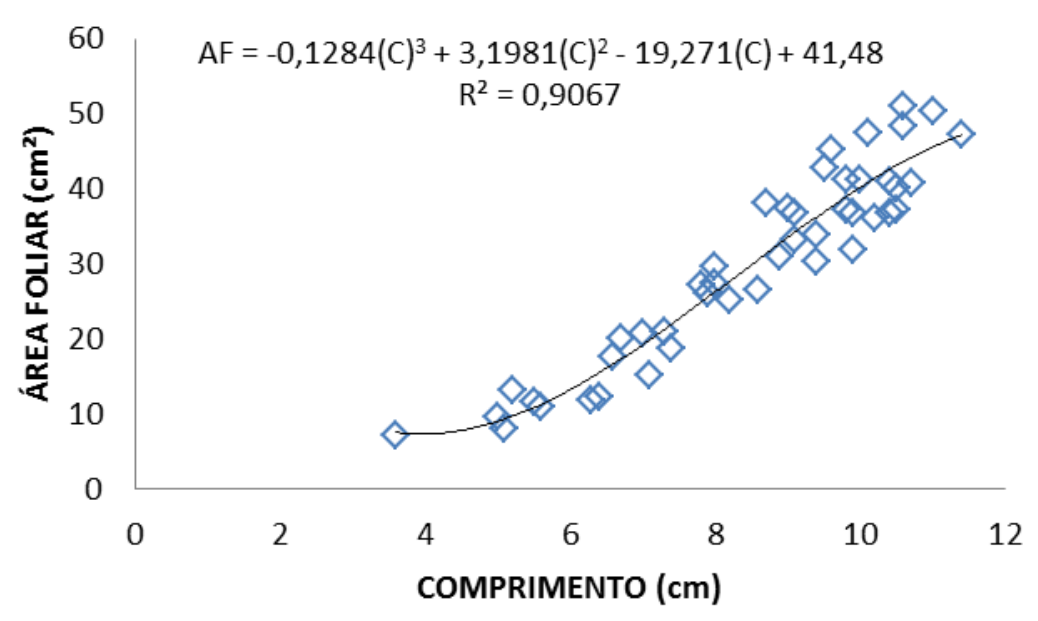

(A)

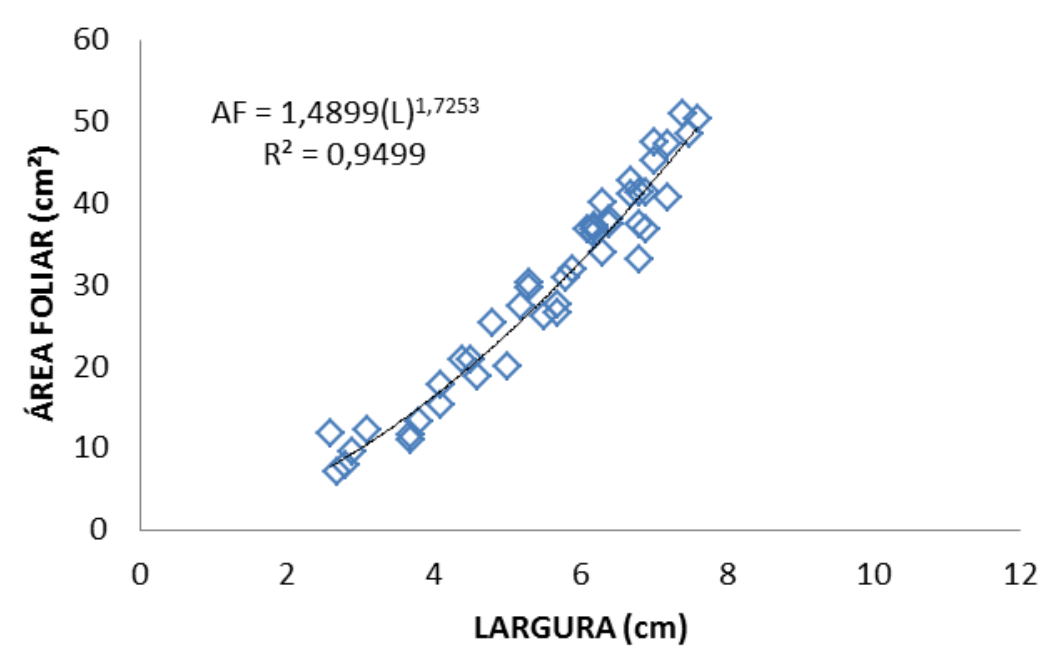

(B)

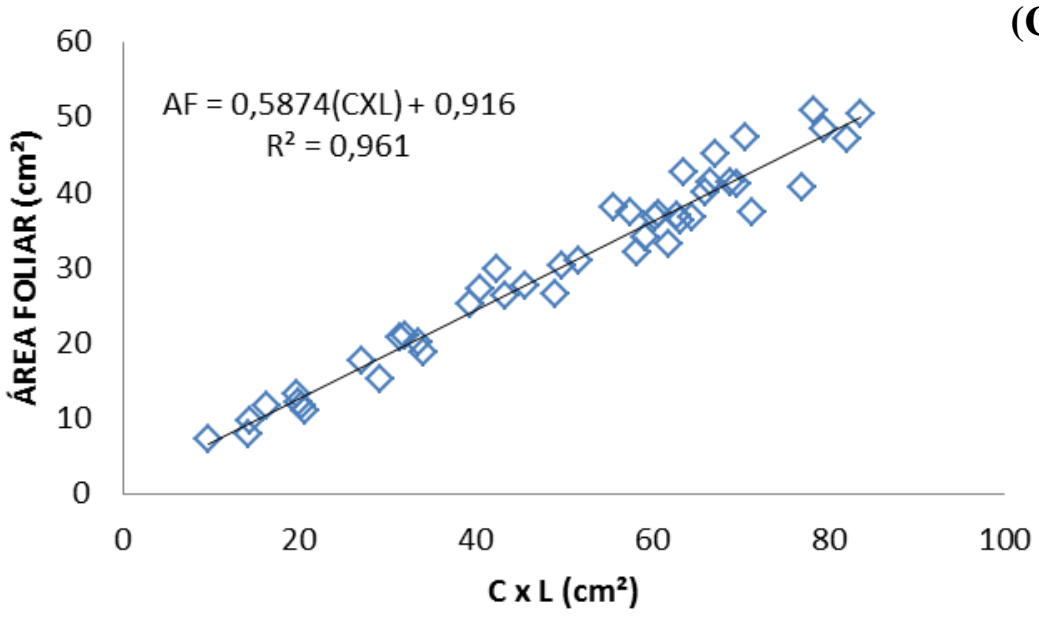

Quando se realizou o ajuste dos modelos matemáticos para as fases fenológicas que compreende o surgimento dos botões florais $\left(\mathrm{F}_{2}\right)$ e o ponto de colheita $\left(\mathrm{F}_{4}\right)$, observou-se que todas as equações ajustadas tiveram baixo desempenho, diferentemente da fase vegetativa e maturação fisiológica, (Tabela 1). Assim, os modelos mais precisos foram quadráticos para a fase $F_{1}$, o cúbico, potencia e linear para a fase $F_{3}$, com coeficientes de correlação linear de Pearson $(r)$ e de determinação $\left(R^{2}\right)$ mais próximos de um, menor erro 
absoluto médio (EAM) e raiz do quadrado médio do erro (RQME) e, índices d de Willmott e CS mais próximos de um, como apresentado na Tabela 1.

Tabela 1. Variáveis independentes (x), coeficientes de correlação linear de Pearson (r) e de determinação $\left(\mathrm{R}^{2}\right)$, obtidos na regressão linear ajustada entre a área foliar estimada (variável dependente) e a observada (variável independente). Erro absoluto médio (EAM), raiz do quadrado médio do erro (RQME), índice d de Willmott e índice CS, calculados com base nas áreas foliares, observada e estimada de 216 folhas de feijão caupi cultivar BRS Potengi.

(Continua)

\begin{tabular}{|c|c|c|c|c|c|c|c|c|}
\hline $\begin{array}{c}\text { FASES } \\
\text { FENOLÓGICA }\end{array}$ & MODELOS & $\mathbf{X}$ & $\mathbf{R}$ & $\mathbf{R}^{2}$ & EAM & RQME & d & Cs \\
\hline $\mathrm{F} 1$ & QUADRÁTICO & $\mathrm{L}$ & 0,942 & 0,887 & 0,849 & 1,150 & 0,960 & 0,851 \\
\hline $\mathrm{F} 1$ & CÚBICO & $\mathrm{L}$ & 0,942 & 0,887 & 0,856 & 1,162 & 0,959 & 0,850 \\
\hline $\mathrm{F} 1$ & QUADRÁTICO & $\mathrm{CxL}$ & 0,935 & 0,875 & 0,929 & 1,565 & 0,946 & 0,828 \\
\hline $\mathrm{F} 1$ & CÚBICO & $\mathrm{CxL}$ & 0,926 & 0,857 & 1,039 & 1,366 & 0,934 & 0,800 \\
\hline $\mathrm{F} 2$ & EXPONENCIAL & $\mathrm{C}$ & 0,370 & 0,137 & 14,928 & 38,449 & 0,477 & 0,065 \\
\hline $\mathrm{F} 2$ & LINEAR & $\mathrm{C}$ & 0,422 & 0,178 & 14,243 & 37,834 & 0,433 & 0,077 \\
\hline $\mathrm{F} 2$ & QUADRÁTICO & $\mathrm{C}$ & 0,411 & 0,169 & 14,058 & 37,599 & 0,452 & 0,076 \\
\hline $\mathrm{F} 2$ & CÚBICO & $\mathrm{C}$ & 0,421 & 0,177 & 14,037 & 37,530 & 0,455 & 0,081 \\
\hline $\mathrm{F} 2$ & POTENCIA & $\mathrm{C}$ & 0,404 & 0,163 & 14,054 & 37,780 & 0,459 & 0,075 \\
\hline $\mathrm{F} 2$ & EXPONENCIAL & $\mathrm{L}$ & 0,355 & 0,126 & 16,987 & 40,968 & 0,429 & 0,054 \\
\hline $\mathrm{F} 2$ & LINEAR & $\mathrm{L}$ & 0,387 & 0,150 & 13,822 & 38,554 & 0,750 & 0,113 \\
\hline $\mathrm{F} 2$ & QUADRÁTICO & $\mathrm{L}$ & 0,373 & 0,139 & 13,768 & 38,985 & 0,429 & 0,060 \\
\hline $\mathrm{F} 2$ & CÚBICO & $\mathrm{L}$ & 0,374 & 0,140 & 13,767 & 38,976 & 0,430 & 0,060 \\
\hline $\mathrm{F} 2$ & POTENCIA & $\mathrm{L}$ & 0,375 & 0,141 & 13,801 & 38,979 & 0,428 & 0,060 \\
\hline $\mathrm{F} 2$ & EXPONENCIAL & $\mathrm{CxL}$ & 0,341 & 0,116 & 14,422 & 39,511 & 0,472 & 0,055 \\
\hline $\mathrm{F} 2$ & LINEAR & $\mathrm{CxL}$ & 0,399 & 0,159 & 12,585 & 38,271 & 0,441 & 0,070 \\
\hline $\mathrm{F} 2$ & QUADRÁTICO & $\mathrm{CxL}$ & 0,399 & 0,159 & 12,958 & 38,689 & 0,446 & 0,071 \\
\hline $\mathrm{F} 2$ & CÚBICO & $\mathrm{CxL}$ & 0,398 & 0,158 & 12,605 & 38,378 & 0,450 & 0,071 \\
\hline $\mathrm{F} 2$ & POTENCIA & $\mathrm{CxL}$ & 0,399 & 0,159 & 12,594 & 38,278 & 0,450 & 0,072 \\
\hline F2 & L. INTERCEPTO & $\mathrm{CxL}$ & 0,399 & 0,159 & 12,586 & 38,267 & 0,452 & 0,072 \\
\hline F3 & EXPONENCIAL & $\mathrm{C}$ & 0,836 & 0,700 & 5,096 & 9,593 & 0,899 & 0,629 \\
\hline F3 & CÚBICO & $\mathrm{C}$ & 0,915 & 0,838 & 3,497 & 5,940 & 0,946 & 0,792 \\
\hline $\mathrm{F} 3$ & POTENCIA & $\mathrm{C}$ & 0,897 & 0,804 & 3,701 & 6,374 & 0,944 & 0,759 \\
\hline F3 & EXPONENCIAL & $\mathrm{L}$ & 0,888 & 0,788 & 3,745 & 6,697 & 0,941 & 0,741 \\
\hline F3 & LINEAR & $\mathrm{L}$ & 0,906 & 0,820 & 3,517 & 6,020 & 0,943 & 0,773 \\
\hline F3 & QUADRÁTICO & $\mathrm{L}$ & 0,687 & 0,820 & 3,278 & 5,952 & 0,947 & 0,777 \\
\hline F3 & CÚBICO & $\mathrm{L}$ & 0,906 & 0,822 & 3,308 & 5,937 & 0,947 & 0,778 \\
\hline $\mathrm{F} 3$ & POTENCIA & $\mathrm{L}$ & 0,906 & 0,821 & 3,277 & 5,961 & 0,946 & 0,777 \\
\hline F3 & EXPONENCIAL & $\mathrm{CxL}$ & 0,884 & 0,781 & 13,362 & 8,570 & 0,120 & 0,094 \\
\hline F3 & LINEAR & $\mathrm{CxL}$ & 0,933 & 0,870 & 2,130 & 5,070 & 0,961 & 0,836 \\
\hline F3 & LOGARÍTIMICO & $\mathrm{CxL}$ & 0,908 & 0,825 & 3,947 & 6,032 & 0,941 & 0,776 \\
\hline $\mathrm{F} 3$ & QUADRÁTICO & $\mathrm{CxL}$ & 0,933 & 0,871 & 2,316 & 5,082 & 0,963 & 0,839 \\
\hline F3 & CÚBICO & $\mathrm{CxL}$ & 0,932 & 0,869 & 2,551 & 5,171 & 0,965 & 0,838 \\
\hline F3 & POTENCIA & $\mathrm{CxL}$ & 0,933 & 0,871 & 2,293 & 5,078 & 0,963 & 0,839 \\
\hline F3 & L. INTERCEPTO & $\mathrm{CxL}$ & 0,933 & 0,870 & 2,226 & 5,083 & 0,914 & 0,796 \\
\hline $\mathrm{F} 4$ & EXPONENCIAL & $\mathrm{C}$ & 0,486 & 0,236 & 13,141 & 32,387 & 0,533 & 0,126 \\
\hline $\mathrm{F} 4$ & LINEAR & $\mathrm{C}$ & 0,528 & 0,279 & 12,311 & 32,494 & 0,478 & 0,133 \\
\hline $\mathrm{F} 4$ & QUADRÁTICO & $\mathrm{C}$ & 0,528 & 0,279 & 20,679 & 38,883 & 0,410 & 0,114 \\
\hline $\mathrm{F} 4$ & CÚBICO & $\mathrm{C}$ & 0,544 & 0,295 & 11,945 & 32,344 & 0,480 & 0,142 \\
\hline
\end{tabular}


Tabela 1. Variáveis independentes (x), coeficientes de correlação linear de Pearson (r) e de determinação $\left(\mathrm{R}^{2}\right)$, obtidos na regressão linear ajustada entre a área foliar estimada (variável dependente) e a observada (variável independente). Erro absoluto médio (EAM), raiz do quadrado médio do erro (RQME), índice d de Willmott e índice CS, calculados com base nas áreas foliares, observada e estimada de 216 folhas de feijão caupi cultivar BRS Potengi.

(Conclusão)

\begin{tabular}{lcccccccc} 
F4 & POTENCIA & C & 0,957 & 0,915 & 1438,630 & 4514,791 & 0,028 & 0,026 \\
F4 & EXPONENCIAL & L & 0,477 & 0,228 & 13,075 & 32,938 & 0,513 & 0,117 \\
F4 & LINEAR & L & 0,526 & 0,277 & 11,676 & 21,634 & 0,748 & 0,207 \\
F4 & QUADRÁTICO & L & 0,527 & 0,278 & 11,499 & 32,825 & 0,463 & 0,129 \\
F4 & CÚBICO & L & 0,542 & 0,294 & 3,414 & 32,801 & 0,462 & 0,136 \\
F4 & POTENCIA & L & 0,526 & 0,277 & 11,629 & 32,746 & 0,476 & 0,132 \\
F4 & LINEAR & CxL & 0,545 & 0,297 & 3,294 & 32,381 & 0,483 & 0,143 \\
F4 & LOGARÍTIMICO & CxL & 0,157 & 0,025 & 15,867 & 36,891 & 0,322 & 0,008 \\
F4 & QUADRÁTICO & CxL & 0,549 & 0,302 & 10,888 & 32,419 & 0,479 & 0,145 \\
F4 & CÚBICO & CxL & 0,547 & 0,300 & 10,783 & 32,028 & 0,502 & 0,150 \\
F4 & POTENCIA & CxL & $-0,546$ & 0,299 & 33,417 & 49,024 & 0,359 & 0,107 \\
F4 & L. INTERCEPTO & CxL & 0,545 & 0,297 & 10,996 & 32,359 & 0,491 & 0,146 \\
F4 & POTENCIA & C & 0,957 & 0,915 & 1438,630 & 4514,791 & 0,028 & 0,026 \\
F4 & EXPONENCIAL & L & 0,477 & 0,228 & 13,075 & 32,938 & 0,513 & 0,117 \\
F4 & LINEAR & L & 0,526 & 0,277 & 11,676 & 21,634 & 0,748 & 0,207 \\
F4 & QUADRÁTICO & L & 0,527 & 0,278 & 11,499 & 32,825 & 0,463 & 0,129 \\
F4 & CÚBICO & L & 0,542 & 0,294 & 3,414 & 32,801 & 0,462 & 0,136 \\
F4 & POTENCIA & L & 0,526 & 0,277 & 11,629 & 32,746 & 0,476 & 0,132 \\
F4 & LINEAR & CxL & 0,545 & 0,297 & 3,294 & 32,381 & 0,483 & 0,143 \\
F4 & LOGARÍTIMICO & CxL & 0,157 & 0,025 & 15,867 & 36,891 & 0,322 & 0,008 \\
F4 & QUADRÁTICO & CxL & 0,549 & 0,302 & 10,888 & 32,419 & 0,479 & 0,145 \\
F4 & CÚBICO & CxL & 0,547 & 0,300 & 10,783 & 32,028 & 0,502 & 0,150 \\
F4 & POTENCIA & CxL & $-0,546$ & 0,299 & 33,417 & 49,024 & 0,359 & 0,107 \\
F4 & L. INTERCEPTO & CxL & 0,545 & 0,297 & 10,996 & 32,359 & 0,491 & 0,146 \\
\hline & & & & & & & &
\end{tabular}

Para cultivar de feijão caupi BRS Potengi, nos períodos fenológicos $F_{2}$ e $F_{4}$, não foram possíveis, assim, determinar nenhum modelo que estimassem a área foliar com precisão. Dentre os modelos gerados para as fases $F_{1}$ e $F_{3}$ nas Figuras 1 e 2, os coeficientes de determinação foram ( $\left.R^{2}>0,90\right)$, indicando que 90\% das variações observadas na área foliar foram explicadas pelas equações obtidas. Para cada subperíodo do ciclo da planta e dimensão do limbo foliar utilizada na estimativa foliar, observa-se que as equações estimadoras foram diferentes dentro de uma mesma cultivar.

Para a fase de maturação fisiológica apenas o produto da dimensão do limbo foliar $(\mathrm{CxL})$, foi mais precisa para os modelos estimadores de área foliar, que no caso especifico foi o linear. Bianco et al. (2008) na cultura do mentrasto (Ageratum conyzoides L.), mostraram que os modelos estimadores utilizando o produto entre o comprimento e a largura da folha foi o mais preciso para determinar á área foliar da cultura com maior precisão. Pinto et al. (2008), em seu estudo para determinar modelos para estimativa de área foliar de Curcuma alismatifolia e Curcuma zedoaria, observaram que o produto das variáveis comprimento e largura do limbo foliar foi também estatisticamente adequado para estimar área foliar.

Silva et al. (2013) estudando modelos de determinação não destrutiva de área foliar em Pimenteira do Reino, observou também melhores ajustes para os modelos quadráticos e linear, quando leva em consideração CxL como variável independente, como constatado no presente trabalho.

Para a fase $\mathrm{F}_{1}$ considerando as duas variáveis do limbo foliar observaram que a largura no modelo quadrático, foi o que apresentou melhor ajuste Tabela 1. Resultados semelhantes aos encontrados nesse 
trabalho foram evidenciados por Lima et al. (2008) em que a área foliar de feijão caupi pode ser estimada a partir de equações lineares com boa precisão. Toebe et al. (2010) analisando o método de fotos digitais para estimar a área foliar da cultura de crambe, concluiu que a largura da folha é a variável que melhor estima a área foliar da espécie vegetal.

Nas Figuras 3 e 4 encontram-se os modelos linearizados, com base nas áreas foliares reais observados pelos métodos dos discos e a área foliar estimada pelos modelos matemáticos.

Figura 3. Relação entre área foliar observada e estimada pelos modelos de regressão quadráticos (A e B) na fase vegetativa $F_{1}$ obtidos entre a largura e $C x L$ e, a área do limbo foliar de feijão caupi cultivar BRS Potengi, obtidos em Capitão Poço-PA, Brasil, 2012.
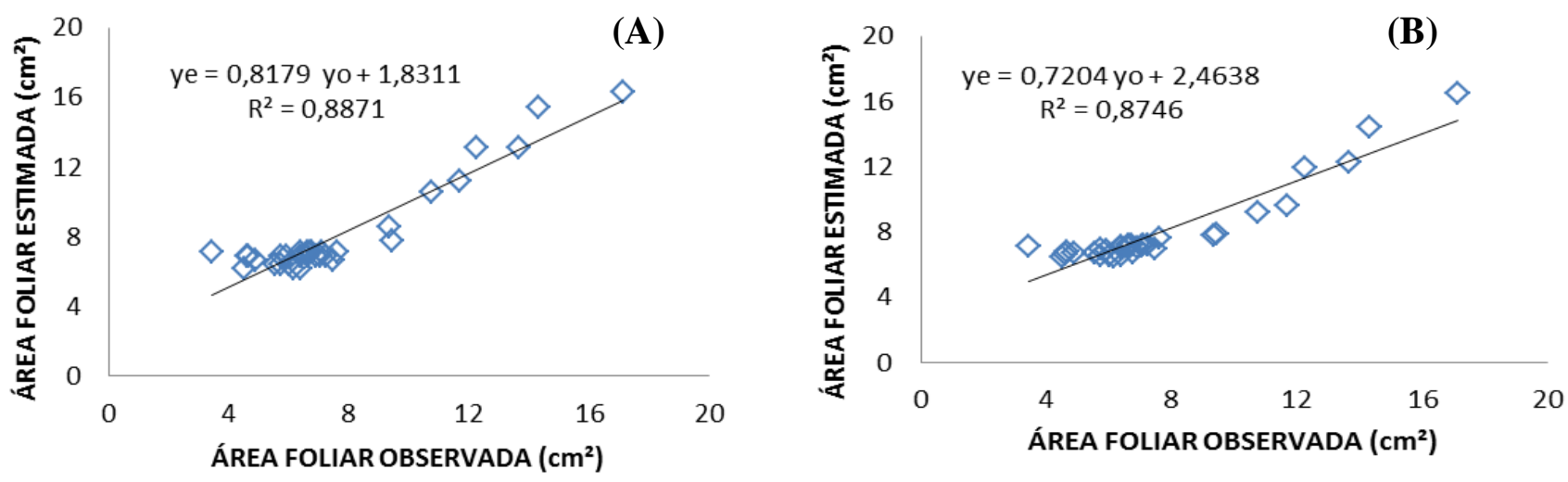

Figura 4. Relação entre área foliar observada e estimada pelos modelos de regressão cúbico potencia e linear $(\mathrm{A}, \mathrm{B}$ e C $)$ para a fase de maturação fisiológica $\left(\mathrm{F}_{3}\right)$ respectivamente, obtidos entre o comprimento, largura e CxL e, a área do limbo foliar de feijão caupi cultivar BRS Potengi, obtidos em Capitão PoçoPA, Brasil, 2012.
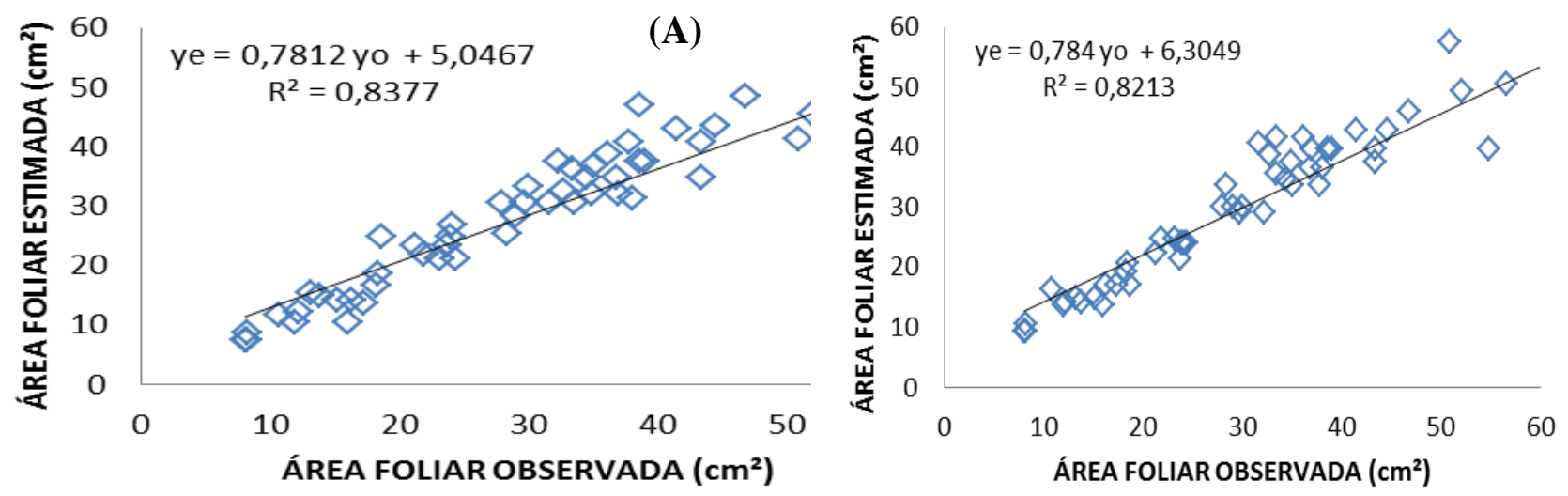

(B)

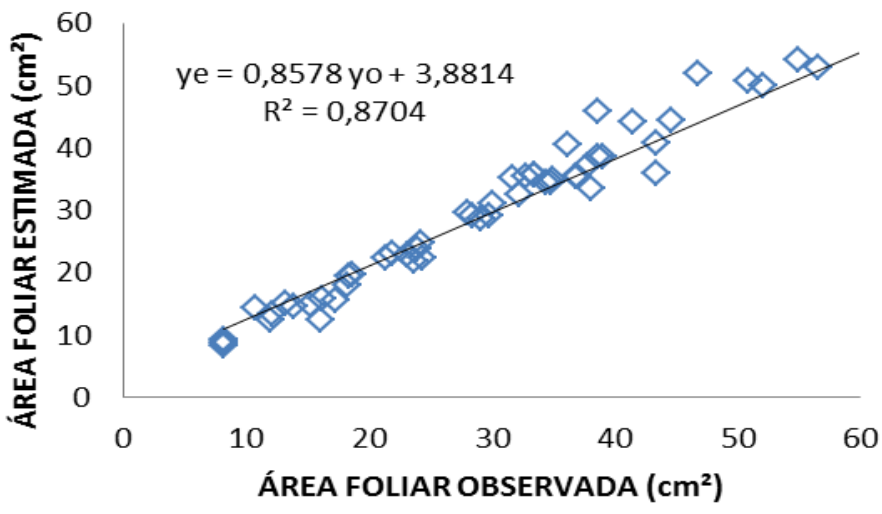

(C) 
Para a cultivar de feijão caupi BRS Tracuateua foi considerado também os modelos com melhor ajusta na determinação da área foliar, sendo que apenas nas fases vegetativa e ponto de colheita se teve a maior precisão dos dados. Nas Figuras 5 e 6 encontram-se os modelos gerados com as respectivas variáveis do limbo foliar da planta.

Figura 5. Modelo de regressão linear, quadrático e linear (A, B e C) para a fase vegetativa $\left(\mathrm{F}_{1}\right)$, obtidas em Capitão Poço-PA, Brasil, 2012.

(A)
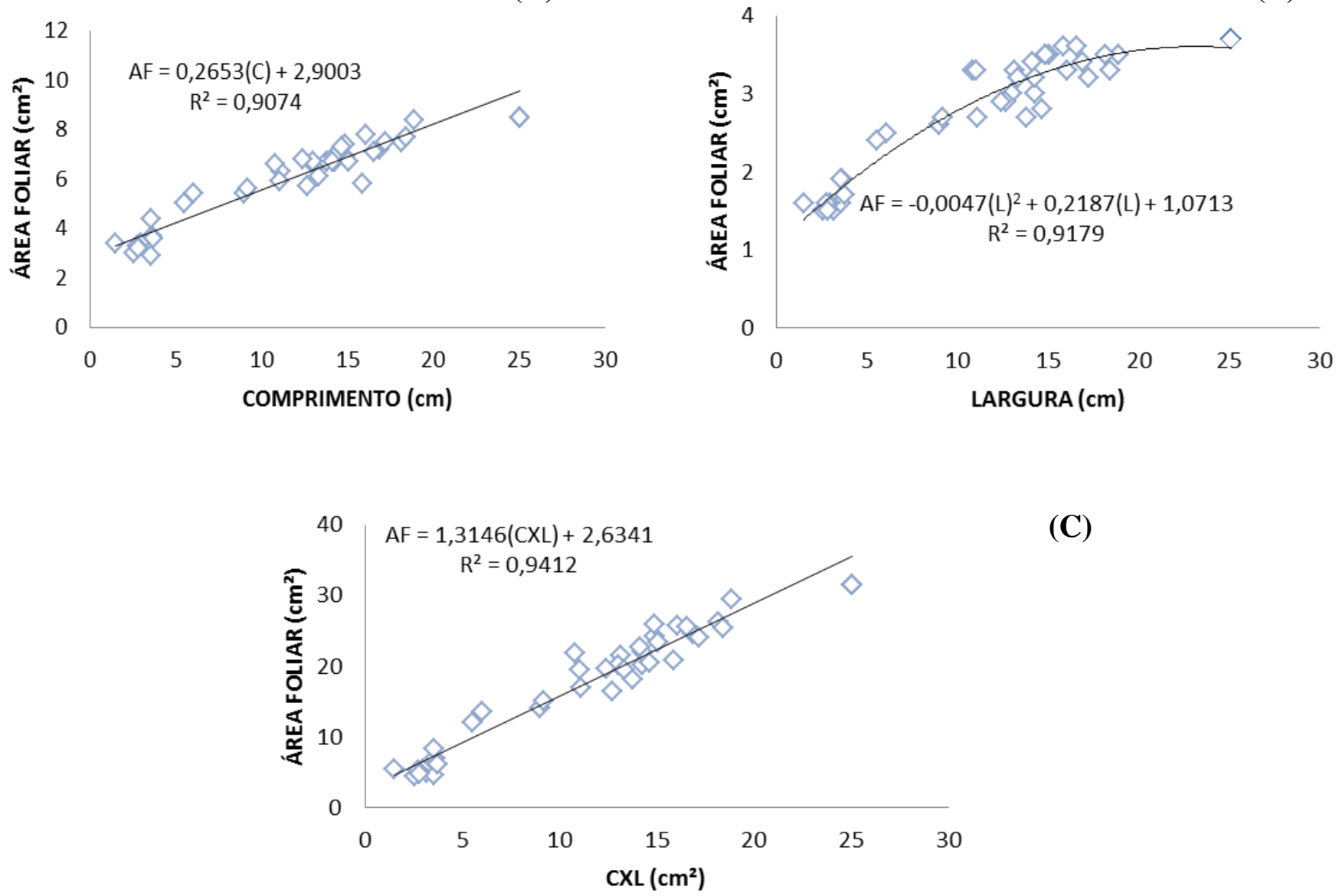

(C)

Figura 6. Modelo de regressão quadrático, potencia e quadrático (A, B e C) para a fase Ponto de colheita $\left(\mathrm{F}_{4}\right)$, obtidas em Capitão Poço-PA, Brasil, 2012.
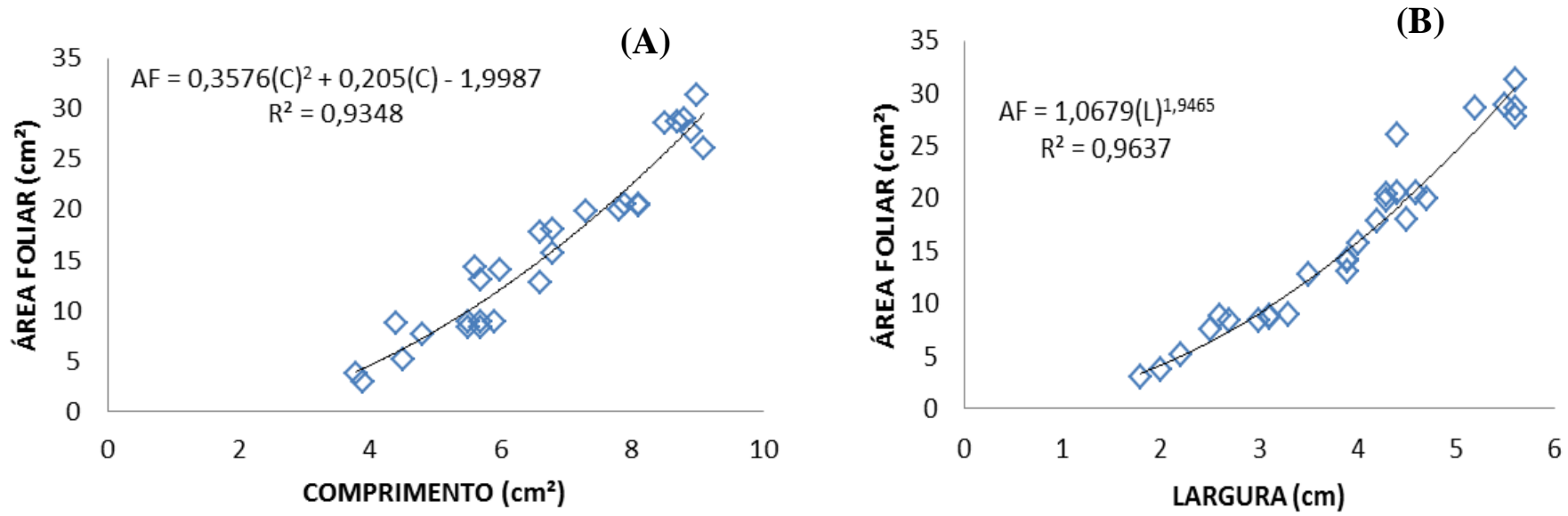


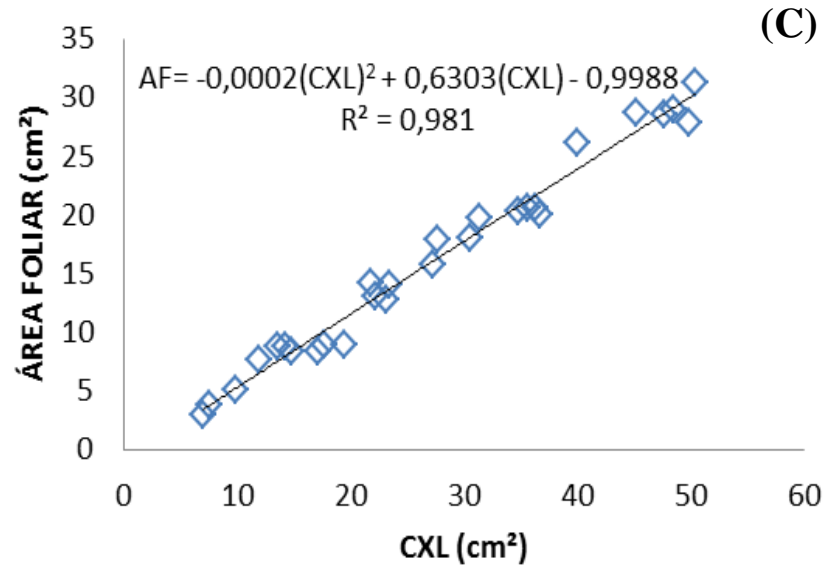

Para a cultivar BRS Tracuateua as fases fenológicas que não obtiveram nenhum modelo matemático eficiente foram as fases surgimento dos botões florais $\left(\mathrm{F}_{2}\right)$ e maturação fisiológica $\left(\mathrm{F}_{3}\right)$, pois quando se fez o ajuste dos modelos todos apresentaram baixo desempenho. Os modelos linearizados com os melhores ajustes foram os da fase vegetativa $\left(\mathrm{F}_{1}\right)$ e ponto de colheita $\left(\mathrm{F}_{4}\right)$ respectivamente Tabela 2 .

Tabela 2. Variáveis independentes (x), coeficientes de correlação linear de Pearson (r) e de determinação $\left(\mathrm{R}^{2}\right)$, obtidos na regressão linear ajustada entre a área foliar estimada (variável dependente) e a observada (variável independente). Erro absoluto médio (EAM), raiz do quadrado médio do erro (RQME), índice d de Willmott e índice CS, calculados com base nas áreas foliares, observada e estimada de 216 folhas de feijão caupi cultivar BRS Tracuateua.

(Continua)

\begin{tabular}{ccccccccc}
\hline $\begin{array}{c}\text { FASES } \\
\text { FENOLÓGICA }\end{array}$ & MODELOS & $\mathbf{X}$ & $\mathbf{R}$ & $\mathbf{R}^{\mathbf{2}}$ & $\mathbf{E A M}$ & $\mathbf{R Q M E}$ & $\mathbf{D}$ & $\mathbf{C s}$ \\
\hline F1 & LINEAR & $\mathrm{C}$ & 0,808 & 0,653 & 4,604 & 6,484 & 0,488 & 0,319 \\
F1 & LOGARÍTIMICO & $\mathrm{C}$ & 0,797 & 0,635 & 4,336 & 6,162 & 0,498 & 0,316 \\
F1 & QUADRÁTICO & $\mathrm{C}$ & 0,807 & 0,652 & 4,593 & 6,436 & 0,485 & 0,316 \\
F1 & CÚBICO & $\mathrm{C}$ & 0,806 & 0,650 & 4,538 & 6,375 & 0,489 & 0,318 \\
F1 & POTENCIA & $\mathrm{C}$ & 0,803 & 0,645 & 4,505 & 6,344 & 0,489 & 0,316 \\
F1 & LOGARÍTIMICO & $\mathrm{L}$ & 0,925 & 0,855 & 7,175 & 8,604 & 0,450 & 0,385 \\
F1 & QUADRÁTICO & $\mathrm{L}$ & 0,933 & 0,870 & 7,029 & 8,548 & 0,444 & 0,386 \\
F1 & CÚBICO & $\mathrm{L}$ & 0,933 & 0,871 & 7,088 & 8,589 & 0,444 & 0,387 \\
F1 & POTENCIA & $\mathrm{L}$ & 0,931 & 0,868 & 7,082 & 8,578 & 0,445 & 0,386 \\
F1 & LINEAR & $\mathrm{CxL}$ & 0,944 & 0,892 & 10,910 & 11,831 & 0,583 & 0,519 \\
F1 & LOGARÍTIMICO & $\mathrm{CxL}$ & 0,906 & 0,820 & 10,851 & 11,118 & 0,542 & 0,445 \\
F1 & QUADRÁTICO & $\mathrm{CxL}$ & 0,927 & 0,859 & 10,529 & 11,106 & 0,578 & 0,497 \\
F1 & CÚBICO & $\mathrm{CxL}$ & 0,927 & 0,858 & 10,454 & 11,004 & 0,580 & 0,498 \\
F1 & POTENCIA & $\mathrm{CxL}$ & 0,942 & 0,887 & 10,763 & 11,550 & 0,583 & 0,517 \\
F1 & L. INTERCEPTO & $\mathrm{CxL}$ & 0,944 & 0,892 & 10,648 & 12,113 & 0,591 & 0,527 \\
F2 & LINEAR & $\mathrm{C}$ & 0,420 & 0,176 & 28,653 & 43,772 & 0,340 & 0,060 \\
F2 & QUADRÁTICO & $\mathrm{C}$ & 0,489 & 0,239 & 28,983 & 43,967 & 0,477 & 0,114 \\
F2 & CÚBICO & $\mathrm{C}$ & 0,422 & 0,178 & 29,089 & 43,991 & 0,343 & 0,061 \\
F2 & POTENCIA & $\mathrm{C}$ & 0,424 & 0,180 & 29,111 & 43,964 & 0,652 & 0,117 \\
F2 & LINEAR & $\mathrm{L}$ & 0,573 & 0,328 & 31,857 & 45,998 & 0,339 & 0,111 \\
F2 & LOGARÍTIMICO & $\mathrm{L}$ & 0,536 & 0,288 & 29,082 & 5,393 & 0,990 & 0,285 \\
F2 & QUADRÁTICO & $\mathrm{L}$ & 0,571 & 0,326 & 32,389 & 46,330 & 0,340 & 0,111 \\
F2 & CÚBICO & $\mathrm{L}$ & 0,571 & 0,326 & 32,383 & 46,326 & 0,340 & 0,111 \\
F2 & POTENCIA & $\mathrm{L}$ & 0,558 & 0,311 & 32,530 & 46,380 & 0,342 & 0,106 \\
F2 & LINEAR & $\mathrm{CxL}$ & 0,497 & 0,247 & 58,762 & 67,461 & 0,430 & 0,106 \\
F2 & QUADRÁTICO & $\mathrm{CxL}$ & 0,573 & 0,328 & 25,217 & 40,656 & 0,365 & 0,120 \\
F2 & CÚBICO & $\mathrm{CxL}$ & 0,488 & 0,238 & 56,334 & 63,427 & 0,428 & 0,102 \\
F2 & POTENCIA & $\mathrm{CxL}$ & 0,498 & 0,248 & 52,379 & 66,238 & 0,430 & 0,107
\end{tabular}


Tabela 2. Variáveis independentes (x), coeficientes de correlação linear de Pearson (r) e de determinação $\left(\mathrm{R}^{2}\right)$, obtidos na regressão linear ajustada entre a área foliar estimada (variável dependente) e a observada (variável independente). Erro absoluto médio (EAM), raiz do quadrado médio do erro (RQME), índice d de Willmott e índice CS, calculados com base nas áreas foliares, observada e estimada de 216 folhas de feijão caupi cultivar BRS Tracuateua.

(Conclusão)

\begin{tabular}{|c|c|c|c|c|c|c|c|c|}
\hline $\mathrm{F} 2$ & L. INTERCEPTO & $\mathrm{CxL}$ & 1,000 & 1,000 & 24,551 & 34,019 & 0,868 & 0,868 \\
\hline F3 & EXPONENCIAL & $\mathrm{C}$ & $-0,015$ & 0,002 & 39,953 & 214,282 & 1,935 & 0,039 \\
\hline F3 & LINEAR & $\mathrm{C}$ & 0,010 & 0,001 & 31,951 & 213,197 & 0,070 & 0,007 \\
\hline F3 & QUADRÁTICO & $\mathrm{C}$ & $-0,009$ & 0,001 & 36,907 & 213,518 & 0,067 & 0,005 \\
\hline F3 & CÚBICO & $\mathrm{C}$ & $-0,015$ & 0,002 & 39,090 & 213,962 & 0,066 & 0,132 \\
\hline F3 & POTENCIA & $\mathrm{C}$ & 0,004 & 0,002 & 33,625 & 213,325 & 0,071 & 0,142 \\
\hline F3 & EXPONENCIAL & $\mathrm{L}$ & 0,111 & 0,012 & 32,252 & 212,188 & 0,075 & 0,001 \\
\hline F3 & LINEAR & $\mathrm{L}$ & 0,126 & 0,016 & 31,920 & 212,483 & 0,076 & 0,001 \\
\hline F3 & LOGARÍTIMICO & $\mathrm{L}$ & 0,116 & 0,014 & 32,775 & 212,687 & 0,016 & 0,002 \\
\hline F3 & QUADRÁTICO & $\mathrm{L}$ & 0,126 & 0,016 & 31,451 & 212,385 & 0,077 & 0,001 \\
\hline F3 & CÚBICO & $\mathrm{L}$ & 0,124 & 0,016 & 31,498 & 212 & 0,077 & 0,001 \\
\hline F3 & POTENCIA & $\mathrm{L}$ & 0,126 & 0,016 & 31,446 & 212,367 & 0,077 & 0,001 \\
\hline F3 & EXPONENCIAL & $\mathrm{CxL}$ & $-0,021$ & 0,001 & 38,743 & 213,316 & 0,068 & 0,006 \\
\hline F3 & LINEAR & $\mathrm{CxL}$ & 0,058 & 0,003 & 31,590 & 212,699 & 0,073 & 0,002 \\
\hline F3 & L. INTERCEPTO & $\mathrm{CxL}$ & 0,058 & 0,003 & 31,696 & 212 & 0,008 & 0,003 \\
\hline $\mathrm{F} 3$ & LOGARÍTIMICO & CxL & 0,086 & 0,007 & 32,001 & 212,856 & 0,077 & 0,001 \\
\hline F3 & QUADRÁTICO & $\mathrm{CxL}$ & 0,051 & 0,003 & 32,145 & 212 & 0,072 & 0,002 \\
\hline F3 & CÚBICO & $\mathrm{CxL}$ & 0,035 & 0,001 & 0,9 & 212 & 0,067 & 0,008 \\
\hline F3 & POTENCIA & $\mathrm{CxL}$ & 0,059 & 0,004 & 31,323 & 212,738 & 0,073 & 0,003 \\
\hline $\mathrm{F} 4$ & LINEAR & $\mathrm{C}$ & 0,854 & 0,729 & 4,069 & 6,635 & 0,916 & 0,668 \\
\hline $\mathrm{F} 4$ & QUADRÁTICO & $\mathrm{C}$ & 0,938 & 0,880 & 4,696 & & 0,942 & 0,830 \\
\hline F4 & CÚBICO & $\mathrm{C}$ & 0,910 & 0,829 & 107,264 & 10,357 & 0,886 & 0,735 \\
\hline $\mathrm{F} 4$ & POTENCIA & $\mathrm{C}$ & 0,927 & 0,859 & 6,147 & 9,159 & 0,905 & 0,778 \\
\hline F4 & EXPONENCIAL & $\mathrm{L}$ & 0,956 & 0,914 & 14,969 & 17,069 & 0,572 & 0,522 \\
\hline F4 & LINEAR & $\mathrm{L}$ & 0,962 & 0,926 & 3,182 & 4,257 & 0,964 & 0,892 \\
\hline F4 & QUADRÁTICO & $\mathrm{L}$ & 0,940 & 0,884 & 43,950 & 49,672 & 0,422 & 0,373 \\
\hline F4 & CÚBICO & $\mathrm{L}$ & $-0,858$ & 0,735 & 5075,767 & 8588,017 & 0,004 & 0,003 \\
\hline F4 & POTENCIA & $\mathrm{L}$ & 0,967 & 0,935 & 2,359 & 3,253 & 0,982 & 0,917 \\
\hline F4 & LINEAR & $\mathrm{CxL}$ & 0,973 & 0,947 & 2,642 & 3,727 & 0,979 & 0,927 \\
\hline F4 & L. INTERCEPTO & $\mathrm{CxL}$ & 0,973 & 0,947 & 2,412 & 3,358 & 0,982 & 0,930 \\
\hline F4 & LOGARÍTIMICO & $\mathrm{CxL}$ & 0,554 & 0,307 & 5,780 & 10,574 & 0,746 & 0,229 \\
\hline $\mathrm{F} 4$ & QUADRÁTICO & CxL & 0,974 & 0,948 & 2,562 & & 0,981 & 0,930 \\
\hline F4 & CÚBICO & $\mathrm{CxL}$ & 0,976 & 0,953 & & 3,414 & 0,979 & 0,933 \\
\hline F4 & POTENCIA & $\mathrm{CxL}$ & 0,970 & 0,940 & 3,173 & 4,782 & 0,968 & 0,911 \\
\hline
\end{tabular}

$\mathrm{Na}$ fase vegetativa dentre os três modelos o que apresentou o melhor desempenho foi o linear com base no CxL do limbo foliar, apresentando um coeficiente de determinação de 0,892. Já para o ponto de colheita foi o modelo do tipo quadrático utilizando a mesma dimensão do limbo da folha, com $\mathrm{R}^{2}=0,948$. Observa-se, que para cada variável dentro de uma mesma fase ou entre fases do ciclo da planta, houve modelos estimadores de área foliar diferente. Busato et al. (2009) estudando estimativa da área foliar da cultivar de batata Cupido, concluiu que as medidas de comprimento, largura e o produto das mesmas são adequados para estimar a área foliar da cultivar de forma rápida e sem a necessidades de coletar a folha.

Zaffaroni (1981) verificou por análise de regressão múltipla, que a área foliar do feijão macassar (Vigna unguiculata L.) teve melhor correlação com a largura do que com o comprimento do folíolo. Silva et al. (2013) estudando modelos para a estimativa de área foliar de Limoeiro Cravo encontrou também melhor ajuste levando em consideração o produto do $\mathrm{CxL}$ do limbo foliar no modelo do tipo potencia. Nas Figuras 7 e 8 encontram-se os modelos gerados linearizados com base na área foliar observada e estimada, com o melhor ajuste para essa cultivar do presente estudo. 
Figura 7. Relação entre área foliar observada e estimada pelos modelos de regressão linear, quadrático e linear (A, B e C) na fase vegetativa $\mathrm{F}_{1}$ obtidos entre o comprimento, largura e $\mathrm{CxL}$ e, a área do limbo foliar de feijão caupi cultivar BRS Tracuateua respectivamente, obtidos em Capitão Poço-PA, Brasil, 2012
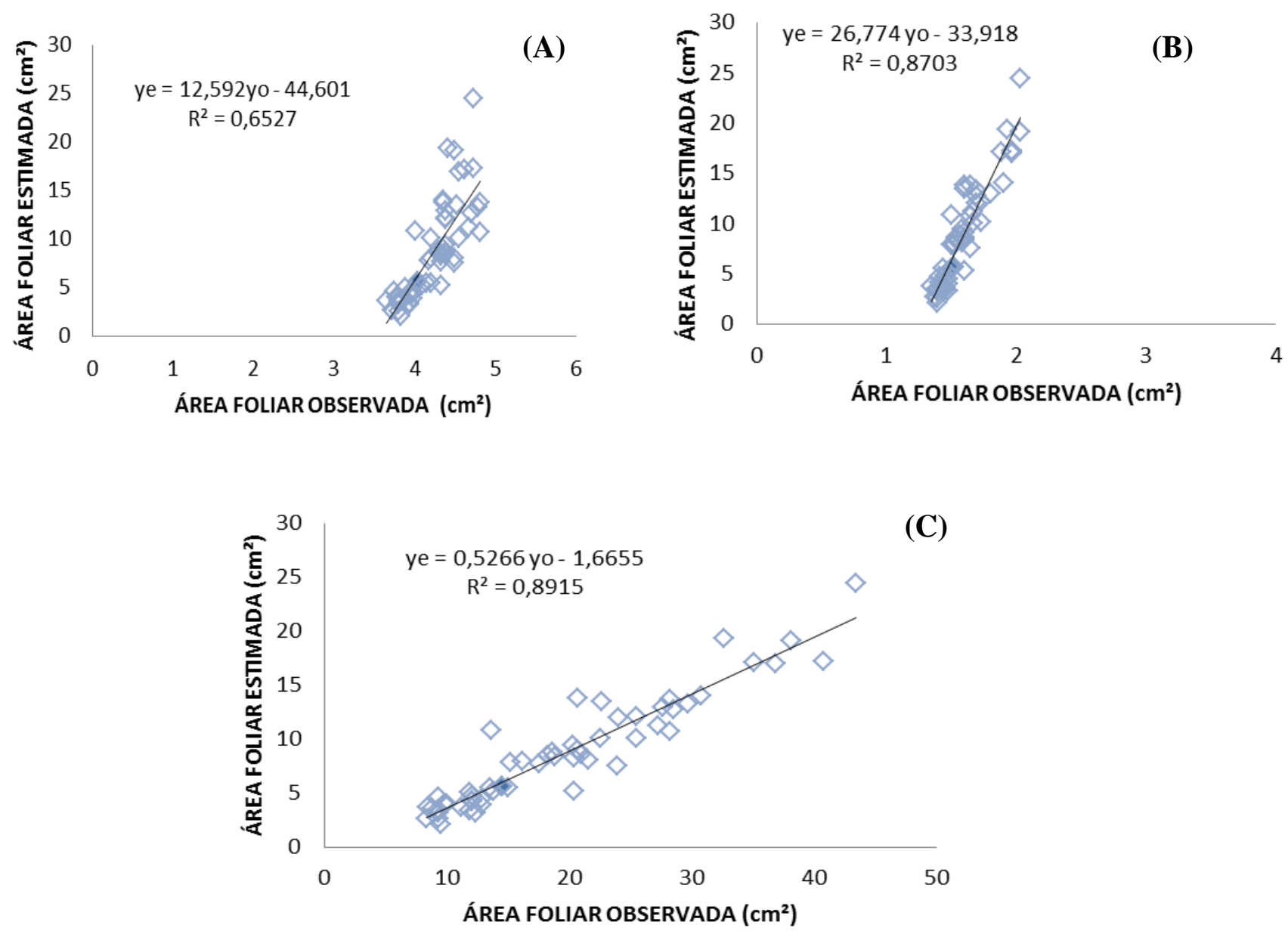

Figura 8. Relação entre área foliar observada e estimada pelos modelos de regressão quadrático, potencia e quadrático (A, B e C) na fase fenológica ponto de colheita $\mathrm{F}_{4}$ obtida entre o comprimento, largura e CxL e, a área do limbo foliar de feijão caupi cultivar BRS Tracuateua respectivamente, obtidos em Capitão Poço-PA, Brasil, 2012.

(A)

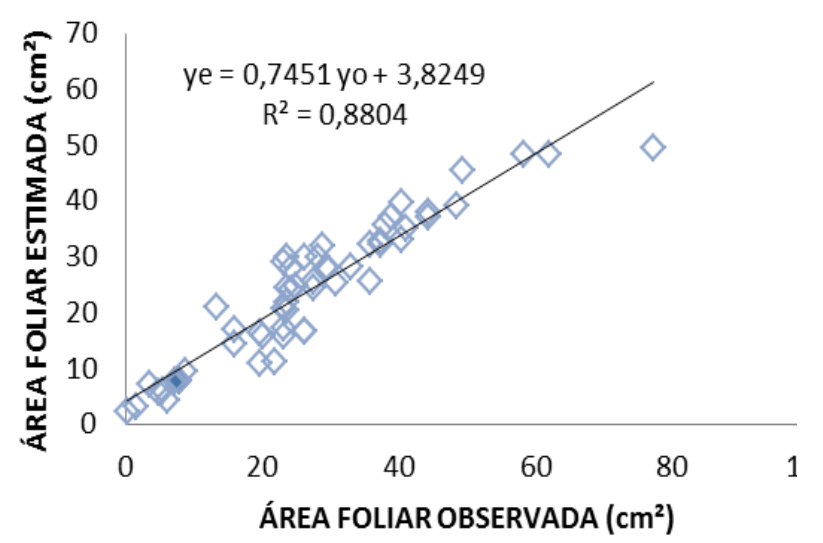

(B)

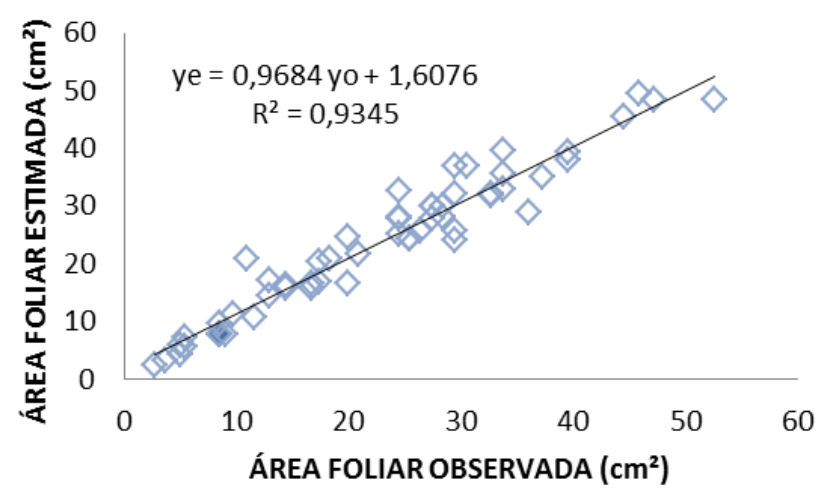




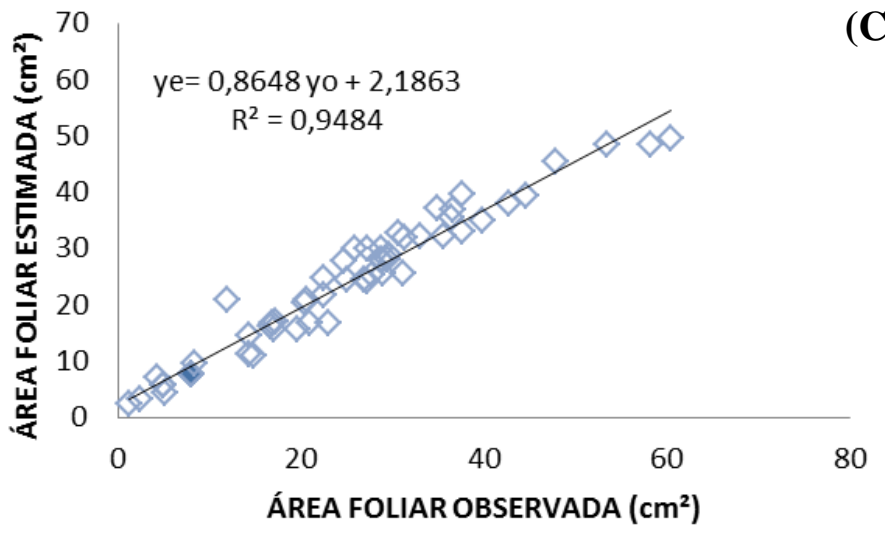

(C)

$\mathrm{O}$ uso das medidas lineares das folhas, tanto largura quanto comprimento, ou o produto delas, podem permitir o monitoramento do crescimento e da expansão foliar da mesma planta, desde o início até o fim do ciclo (SILVA et al., 2008), reduzindo a variabilidade experimental associada com procedimentos de amostragens destrutivas (SILVA et al., 1998). Este procedimento pode ser realizado no campo, de forma simples, rápida, fácil e menos onerosa (SILVA et al., 2008). Vários trabalhos têm relatado o uso de modelos matemáticos para estimar a área foliar com base nas dimensões da folha de diversas espécies, sem destruir a amostra (NASCIMENTO et al., 2002; QUEIROGA et al., 2003, SILVA et al., 2008).

Esta técnica é uma importante ferramenta para a avaliação da área foliar de diversas espécies. O uso de medidas lineares, comprimento e largura das folhas e o produto de ambas as dimensões em modelos matemáticos para estimar a área foliar é um método não destrutivas, de boa precisão e baixo custo, eliminando a disponibilidade de medidores de área foliar caros ou a realização de demoradas reconstruções geométricas, pois a área foliar é uma característica fácil de quantificar em tempo real, no próprio campo, sem necessidade de coletar a folha ou destruir a planta (FONTES; ARAÚJO, 2007).

Resultados semelhantes aos encontrados nesse trabalho foram verificados por Figueiredo et al. (2012) onde as medidas de comprimento e largura das folhas são adequados para estimar a área foliar do feijão da espécie (Phaseolus vulgaris L.) cultivar Pérola de forma rápida e sem a necessidades de coletar a folha, sendo que a regressão do tipo potencial apresentou melhor ajuste para todos os modelos testados, com exceção do produto de comprimento pela largura em que o ajuste linear também apresentou excelente correlação.

\section{CONCLUSÃO}

Para a cultivar BRS Potengi as medidas de área foliar podem ser estimadas com bom desempenho, a partir de equações quadrático, cúbico, potencia e linear.

A área foliar para a fase vegetativa $\left(\mathrm{F}_{1}\right)$ pode ser estimada pelas seguintes equações: $\mathrm{AF}=$ 1,7681(L) ${ }^{2}-4,5477(\mathrm{~L})+8,9043 ; \mathrm{AF}=0,0423(\mathrm{CxL})^{2}-0,5461(\mathrm{CxL})+8,2585$; e, para a maturação fisiológica $\left(\mathrm{F}_{3}\right) \mathrm{AF}=-0,1284(\mathrm{C})^{3}+3,1981(\mathrm{C})^{2}-19,271(\mathrm{C})+41,48 ; \mathrm{AF}=1,4899(\mathrm{~L})^{1,7253} ; \mathrm{AF}=$ $0,5874(\mathrm{CxL})+0,916$.

Para a cultivar BRS Tracuateua os modelos matemáticos de melhor desempenho foram o linear, quadrático e potencia. Para a fase vegetativa $\left(\mathrm{F}_{1}\right)$ a área foliar pode ser estimada pelas equações: $\mathrm{AF}=$ $0,2653(\mathrm{C})+2,9003 ; \mathrm{AF}=-0,0047(\mathrm{~L})^{2}+0,2187(\mathrm{~L})+1,0713 ; \mathrm{AF}=1,3146(\mathrm{CxL})+2,6341 ; \mathrm{e}$, para o ponto de colheita $\left(\mathrm{F}_{4}\right) \mathrm{AF}=0,3576(\mathrm{C})^{2}+0,205(\mathrm{C})-1,9987 ; \mathrm{AF}=1,0679(\mathrm{~L})^{1,9465} ; \mathrm{AF}=-0,0002(\mathrm{CxL})^{2}+$ $0,6303(\mathrm{CxL})-0,9988$. 


\section{REFERÊNCIAS}

BIANCO, S.; BIANCO, M. S.; CARVALHO, L. B. Estimativa da área foliar de Ageratum conyzoides usando dimensões lineares do limbo foliar. Acta Scientiarum Agronomy, v. 30, n. 4, p. 519-523, 2008. http://dx.doi.org/10.4025/actasciagron.v30i4.5311.

BLANCO, F. F.; FOLEGATTI, M. V. Estimation of leaf area for greenhouse cucumber by linear measurements under salinity and grafting. Scientia Agrícola, v. 62, n. 4, p. 305-309, 2005. http://dx.doi.org/10.1590/S0103-90162005000400001.

BUSATO C. et al. Estimativa da área foliar da cultivar de batata Cupido. Horticultura Brasileira, v. 27, n. 2, p. 3570-3573, 2009.

CAMARGO, A. P.; SENTELHAS, P. C. Avaliação do desempenho de diferentes métodos de estimativa da evapotranspiração potencial no estado de São Paulo, Brasil. Revista Brasileira de Agrometeorologia, v. 5, n. 1, p. 89-97, 1997.

EMBRAPA. Recomendação de Adubação e calagem para o Estado do Pará. Boletim, 2010.

FIGUEIREDO, E. S.; SANTOS, M. E.; GARCIA, A. Modelos de determinação não destrutivo da área foliar do feijoeiro comum (Phaseolus vulgaris L.). Nucleus, v.9, n. 1, p. 79-84, 2012. http://dx.doi.org/ $\underline{10.3738 / 1982.2278 .749}$

FONTES P. C. R; ARAÚJO, C. Adubação nitrogenada de hortaliças: princípios e práticas com o tomateiro. Viçosa: UFV, 2007. 148 p.

LIMA, C. J. G. S. et al. Modelos matemáticos para estimativa de área foliar de feijão caupi. Revista Caatinga, v. 21, p. 120-127, 2008.

LUCENA, R. R. M. et al. Medição de área foliar de aceroleira. Revista Caatinga, v. 24, n. 2, p. 40-45, 2011.

NASCIMENTO, I. B. et al. Estimativa da área foliar do meloeiro. Horticultura Brasileira, v. 20, n. 4, p. 555-558, 2002. http://dx.doi.org/10.1590/S0102-05362002000400009 .

OLIVEIRA, F. A. et al. Produção de feijão caupi em função da salinidade e regulador de crescimento. Revista Brasileira de Engenharia Agrícola e Ambiental, v. 9, n. 11, p. 1049-1056, 2015. http://dx.doi.org/10.1590/1807-1929/agriambi.v19n11p1049-1056 .

PINTO, A. C. R. et al. Modelos para estimativa de área foliar de Curcuma alismatifolia e Curcuma zedoaria. Bragantia, v. 67, n. 2, p. 549-552, 2008. http://dx.doi.org/10.1590/S0006-87052008000200033

QUEIROGA, J. L. et al. Estimativa de área foliar do feijão-vagem (Phaseolus vulgaris L.) por meio da largura máxima do folíolo central. Horticultura Brasileira, v. 21, n. 1, p. 64-68, 2003.

http://dx.doi.org/10.1590/S0102-05362003000100013.

SACHET, M. R. et al. Estimativa da área foliar de pessegueiro por método não destrutivo. Ciência Rural, v. 45, n. 12, p. 2161-2163, 2015. http://dx.doi.org/10.1590/0103-8478cr20140185.

SAGRI. Secretaria Executiva de Agricultura do Estado do Pará, 2015. Dados Agropecuários. Disponível em: http://www.sagri.pa.gov.br/ . Acesso em: 10 jun. 2015. 
SANTOS, M. A. S.; REBELLO, F. K.; HOMMA, A. K. O. Fontes de crescimento da produção de feijãocaupi no estado do Pará no período de 1998-2008. In: CONGRESSO NACIONAL DO FEIJÃO-CAUPI, 2. Anais... Belém - PA : Embrapa Amazônia Oriental, 2009. p. 603-607.

SCHWART, G. Manejo sustentável de florestas secundárias: espécies potenciais no Nordeste do Pará, Brasil. Amazônia: Ciência \& Desenvolvimento, v. 3, n. 5, p. 125-147, 2007.

SCHMILDT, E. R. et al. Allometric model for estimating leaf area in clonal varieties of coffee (Coffea canephora). Revista Ciência Agronômica, v. 46, n. 4, p. 740-748, 2015. http://dx.doi.org/10.5935/1806$\underline{6690.20150061}$.

SILVA, R. T. L. et al. Estimativa da área foliar de limoeiro-cravo usando dimensões lineares do limbo foliar. Nucleus, v. 10, n. 1, p. 73-80, 2013. http://dx.doi.org/10.3738//1982.2278.812.

SILVA, M. C. C. et al. Estimativa da área da folha da batateira utilizando medidas lineares. Horticultura Brasileira, v. 26, n. 1, p. 83-87, 2008. http://dx.doi.org/10.1590/S0102-05362008000100016 .

SILVA, R. T. L. et al. Modelos de determinação não - destrutiva de área foliar em pimenteira-do-reino. Journal of Food, Agriculture \& Environment, v.11, n. 2, p. 1480-1486, 2013.

SILVA, N. F. et al. Modelos para estimar a área foliar de abóbora por meio de medidas lineares. Revista Ceres, v. 45, n. 259, p. 287-291, 1998.

TOEBE, M. et al. Estimativa da área foliar de Crambe abyssinica por discos foliares e por fotos digitais. Ciência Rural, v. 40, n. 2, p. 445-448, 2010. http://dx.doi.org/10.1590/S0103-84782010000200036 .

WILLMOTT, C. J. On the validation of models. Physical Geography, v. 2, n. 2, p. 184-194, 1981. 
